\title{
Hyperdopaminergic Mutant Mice Have Higher "Wanting” But Not "Liking" for Sweet Rewards
}

\author{
Susana Peciña, ${ }^{1}$ Barbara Cagniard, ${ }^{3}$ Kent C. Berridge, ${ }^{1}$ J. Wayne Aldridge, ${ }^{1,2}$ and Xiaoxi Zhuang ${ }^{3}$ \\ Departments of ${ }^{1}$ Psychology and ${ }^{2}$ Neurology, University of Michigan, Ann Arbor, Michigan 48109, and ${ }^{3}$ Department of Neurobiology, Pharmacology, and \\ Physiology, University of Chicago, Chicago, Illinois 60637
}

What is the role of dopamine in natural rewards? A genetic mutant approach was taken to examine the consequences of elevated synaptic dopamine on (1) spontaneous food and water intake, (2) incentive motivation and learning to obtain a palatable sweet reward in a runway task, and (3) affective "liking" reactions elicited by the taste of sucrose. A dopamine transporter (DAT) knockdown mutation that preserves only $10 \%$ of normal DAT, and therefore causes mutant mice to have $70 \%$ elevated levels of synaptic dopamine, was used to identify dopamine effects on food intake and reward. We found that hyperdopaminergic DAT knockdown mutant mice have higher food and water intake. In a runway task, they demonstrated enhanced acquisition and greater incentive performance for a sweet reward. Hyperdopaminergic mutant mice leave the start box more quickly than wild-type mice, require fewer trials to learn, pause less often in the runway, resist distractions better, and proceed more directly to the goal. Those observations suggest that hyperdopaminergic mutant mice attribute greater incentive salience ("wanting") to a sweet reward in the runway test. But sucrose taste fails to elicit higher orofacial "liking" reactions from mutant mice in an affective taste reactivity test. These results indicate that chronically elevated extracellular dopamine facilitates "wanting" and learning of an incentive motivation task for a sweet reward, but elevated dopamine does not increase "liking" reactions to the hedonic impact of sweet tastes.

Key words: dopamine; dopamine transporter; DAT knockdown; DAT knock-out; nucleus accumbens; neostriatum; mesolimbic; ventral tegmentum; incentive salience; reward learning; hedonics; affect; pleasure; food intake; ingestive behavior; motivation; addiction; sensitization

\section{Introduction}

Brain mesolimbic dopamine systems play important roles in natural rewards and in drug addiction (Hyman and Malenka, 2001; Koob and Le Moal, 2001; Everitt and Wolf, 2002; Kelley and Berridge, 2002; White, 2002; Robinson and Berridge, 2003). However, the precise contribution of dopamine systems to a reward is unresolved, and there remain several alternative hypotheses. The hedonia hypothesis posits that dopamine mediates the sensory pleasure of food, drugs, and other rewards and suggests that addiction results from withdrawal-induced anhedonia caused by dopamine downregulation (Wise, 1985; Volkow et al., 1999; Koob and Le Moal, 2001). Reward-learning hypotheses posit that dopamine systems are involved in associative learning about rewards and suggest that addiction results from aberrant neural learning in mesocorticolimbic circuits, which causes exaggerated reward predictions or excessive drug-taking habits (Kelley, 1999; Berke and Hyman, 2000; Everitt et al., 2001; Di Chiara, 2002; Everitt and Wolf, 2002; Montague and Berns, 2002; Schultz, 2002). The incentive salience hypothesis posits that do-

Received June 10, 2003; revised Aug. 19, 2003; accepted Aug. 21, 2003.

This research was supported by National Science Foundation Grant IBN 0091661, National Institutes of Health Grants MH63649 and DA015188, the National Alliance for Research on Schizophrenia and Depression, and the Tourette Syndrome Association.

Correspondence should be addressed to Susana Peciña, Department of Psychology, University of Michigan, 525 East University Avenue, Ann Arbor, MI 49109-1109. E-mail: pesu@umich.edu.

Copyright $\odot 2003$ Society for Neuroscience $\quad$ 0270-6474/03/239395-08\$15.00/0 pamine systems modulate the perceived incentive value of reward stimuli, so that more dopamine makes rewards "wanted" more without necessarily being more "liked." It suggests that addiction results from sensitization of mesolimbic systems, which causes excessive "wanting" to take drugs (Berridge and Robinson, 1998; Wyvell and Berridge, 2000; Hyman and Malenka, 2001; Dayan and Balleine, 2002; Salamone and Correa, 2002; McClure et al., 2003; Robinson and Berridge, 2003; Zhang et al., 2003).

Recent development of specific gene knock-outs, including knock-out of the dopamine transporter (DAT) gene that elevates extracellular dopamine, provides useful windows into neural mechanisms of reward (Giros et al., 1996; Sora et al., 1998; Spielewoy et al., 2000; Budygin et al., 2002; Laakso et al., 2002). Brain reward systems originally evolved to respond to natural incentives, such as food and sweet tastes (Kelley and Berridge, 2002). However, assessment of natural foods or sweet rewards is complicated in complete DAT knock-outs because their knock-out mutation causes dwarfism, reducing body size by 44\% from wild-type levels (Bosse et al., 1997). Such suppression of body weight may confound comparisons between mutant and wild-type mice of intake and behavior to food rewards. A better hyperdopaminergic mutant mouse for assessing sweet rewards may be a DAT knockdown mutation (rather than knock-out), which reduces DAT to $10 \%$ of normal in dopamine neurons (Zhuang et al., 2001). DAT knockdown mutant mice have $70 \%$ higher extracellular dopamine levels in striatum than wild-type control mice, yet they readily eat and grow (Zhuang et al., 2001). 
Resolving the role of dopamine in rewards may be aided by examining specific consequences of hyperdopaminergic DAT mutation on components of reward, such as the hedonic impact, learning, and incentive motivation for sweet rewards. Here we assessed the effects of the DAT knockdown hyperdopaminergic mutation on (1) daily food intake and body weight, (2) incentive learning and performance in a runway task for a sweet reward, and (3) affective orofacial "liking" reactions elicited by sucrose taste, which are homologous to affective facial expressions of sucrose liking in human infants.

\section{Materials and Methods}

Subjects. DAT knockdown mutant mice ( $n=12$, male) and wild-type control mice ( $n=12$, male) were generated at the University of Chicago by breeding heterozygous mutants on a $129 \mathrm{~Sv} / \mathrm{J}$ genetic background as described earlier (Zhuang et al., 2001). DAT knockdown was achieved by insertion of additional sequences into the $5^{\prime}$ untranslated region in the second exon of the DAT gene (Slc6a3), resulting in defective transcription and reducing adult DAT expression to $10 \%$ of wild-type levels (Zhuang et al., 2001).

At the University of Michigan, all mice (age, 2-4 months) were housed in same-type pairs $\left(\sim 21^{\circ} \mathrm{C} ; 12 \mathrm{hr}\right.$ light/dark cycle with lights on at 7 A.M.) for at least 2 weeks before behavioral tests. Ad libitum access to food (Purina Rat Chow; Nestlé Purina PetCare, St. Louis, MO) and water (tap water) was always provided except during the incentive runway training of experiment 2.

Food intake, water intake, and body weight (experiment 1). Food and water consumption and body weight stability were assessed daily over 4 weeks in the home cage. Fresh food chow pellets (30-40 gm) were preweighed each day before being given to each pair of mice and weighed again $24 \mathrm{hr}$ later. Cages were inspected for uneaten food crumbs. Water was provided in graduated cylinders accurate to $1 \mathrm{ml}$, and water intake was recorded. Total food and water intake was averaged each day and assigned to each member of the pair as daily scores, and each mouse was individually weighed.

Incentive runway task (experiment 2). Runway learning and performance for a food reward is a traditional behavioral paradigm, which generates acquisition learning curves, as well as running speed and approach trajectory measures of incentive motivation and performance once the task has been learned. The runway apparatus consisted of three compartments: a start box $(15 \times 15 \times 18 \mathrm{~cm})$, a central runway $(60 \times$ $15 \times 18 \mathrm{~cm})$, and a goal box $(15 \times 15 \times 18 \mathrm{~cm})$. Sliding doors separated the start and goal boxes from the runway alley. A video camera tracked the position, route, and running and pausing behavior of a mouse within the runway. The start box could be moved anywhere along the alley to be as close as $15 \mathrm{~cm}$ from the goal box to as far as $75 \mathrm{~cm}$ from the goal box. A dish in the goal box contained a 5 gm piece of sweet breakfast cereal (Froot Loops; Kellogg Co., Battle Creek, MI). Latency to eat the reward was recorded by a video camera. To extinguish any neophobia, mice were habituated to Froot Loops on 3 consecutive days before training.

Before the first runway training trial, all mice were deprived of food for $22 \mathrm{hr}$ (water still available), with food returned for $2 \mathrm{hr}$ immediately after the first runway trial. However, three DAT knockdown mutant mice died within days under the $22 \mathrm{hr}$ deprivation regimen, suggesting that DAT mutants may be too vulnerable to food deprivation stress to use traditional deprivation periods that approach a full day. Therefore, all mice were immediately given a recovery period of $10 \mathrm{~d}$ of ad libitum access to food, and then all subsequent runway training used a shortened food deprivation period of only $8 \mathrm{hr}(8 \mathrm{hr}$ deprived and $16 \mathrm{hr}$ ad libitum access each day; water was always available). The $8 \mathrm{hr}$ deprivation proved fully successful for runway training, and DAT mutants and wild-type mice both appeared to thrive for the duration of runway training and testing.

Runway training was conducted in 11 sessions on alternating days (22 $\mathrm{d}$ training period), with five training trials per session on sessions $1-11$. This was followed by one test trial per session in two further sessions (12 and 13). On the first three training sessions, mice were simply placed directly in the closed goal box and allowed to eat the reward they found there for $5 \mathrm{~min}$. On training session 4, the start box was placed $15 \mathrm{~cm}$ away from the reward. A mouse was placed in the start box for $30 \mathrm{sec}$ with the door closed; then the door was elevated, and the mouse was allowed to proceed into the runway. If a mouse did not leave the start box within 3 min, the mouse was gently pushed toward the goal box. The start box was moved to $30 \mathrm{~cm}$ from the goal on session 5 , to $45 \mathrm{~cm}$ on session 6 , to $60 \mathrm{~cm}$ on session 7 , and to $75 \mathrm{~cm}$ on sessions $8-12$. The task completion speed was calculated for each session by dividing the latency to reach the goal box by the runway length on that day. Exit from the start box was recorded when all four limbs of the animal were outside the start box, and entry of the goal box was recorded when all four limbs of the animal were inside the goal box. Once the mouse had entered the goal box and began eating, it was allowed to consume the reward for $30 \mathrm{sec}$ before being retrieved.

Incentive runway behavior was videotaped for subsequent slowmotion analysis of (1) latency to leave the start box, (2) latency to reach the goal box, (3) number and duration of pauses in the runway, (4) reversals of direction in the runway en route to the goal (involving retracing of steps and usually accompanied by investigatory sniffing), (5) motor running speed while actually running toward the goal (completion speed minus all pauses and reversals), and (6) latency to begin eating the reward once the mouse reached goal box.

Sucrose hedonic impact: affective taste reactivity paradigm (experiment 3). Several taste-elicited affective reactions of mice and rats are homologous to affective facial reactions of human infants, great apes, and monkeys (e.g., rhythmic tongue protrusions to sucrose and gapes to quinine). The probable homology of those facial affective reactions is indicated, for example, by neural programming of identical allometric timing for microstructure features and by the pattern of taxonomic sharing across species, in addition to general similarities of appearance (Berridge, 2000; Steiner et al., 2001). Positive affective orofacial reactions were elicited from each mouse by three sucrose solutions on 3 separate days of taste reactivity testing. A voluntary sucrose-drinking procedure was used to assess taste reactivity, similar to several previous studies (Pelchat et al., 1983; Gray and Cooper, 1995, 1996; Berridge, 2000; Feurté et al., 2000). Voluntary intake was chosen for this study instead of an oral cannulation procedure in case mutants differed from wild-type mice in reaction to surgical stress of cannula implantation (which was avoided by use of the voluntary procedure), a concern prompted by the mutants' higher mortality observed after $22 \mathrm{hr}$ food deprivation.

For taste reactivity testing, each mouse was placed in a plastic cylindrical chamber (diameter, $13 \mathrm{~cm}$ ) with a transparent floor and walls (with multiple ventilation holes at 3,6 , and $9 \mathrm{~cm}$ high). A transparent dish $(2 \times$ $2 \mathrm{~cm}$ ) contained $1 \mathrm{ml}$ of one of three sucrose solutions. A mirror positioned beneath the transparent floor reflected a view of the mouse's face and mouth into a close-up lens of a video camera, which videotaped spontaneous affective facial and body reactions that occurred during and after voluntary intake of sucrose. Mice were habituated to the testing chamber for $10 \mathrm{~min}$ before testing. On each test, sucrose solution $(0.01$, 0.1 , or $1.0 \mathrm{M}$ ) was placed inside the cylinder, and mice were allowed to ingest the sucrose solution for $5 \mathrm{~min}$, during which behavior was videotaped for subsequent analysis. The three concentrations of sucrose were compared in counterbalanced order on three trials spaced $48 \mathrm{hr}$ apart, and each mouse was tested with all sucrose solutions.

Taste reactivity video analysis. Affective reaction patterns were scored in slow-motion video analysis (one frame/30 sec frame by frame to one frame/10 sec actual speed). Positive hedonic reactions included rhythmic midline tongue protrusions (100-120 msec duration in these mice), lateral tongue protrusions (130-180 msec duration), and paw licking (Berridge, 2000). Aversive reaction patterns included gapes, head shakes, forelimb flails, face washing, chin rubs, and paw treading. Neutral reactions (less strongly linked to hedonic or aversive evaluations) were rhythmic mouth movements and passive drip of the solution. To be sure that every component made a comparably weighted contribution to the final hedonic or aversive scores, reactions that occurred in continuous bouts were scored in time bins. Components characterized by bouts of moderate duration, such as rhythmic tongue protrusions, chin rubs, and paw treading, were scored in $2 \mathrm{sec}$ bins (continuous repetitions within $2 \mathrm{sec}$ scored as one occurrence). Components that typically had longer bout durations, such as paw licking, rhythmic mouth movements, passive 
drip, and face washing, were similarly scored in $5 \mathrm{sec}$ bins. Other reactions that can occur as single behaviors were scored as separate occurrences (lateral tongue protrusions, gapes, head shakes, and forelimb flails). These time bins help equate scores of different reactions within a hedonic category, so that more frequent perseverative reactions such as rhythmic mouth movements do not obscure rare but informative reactions such as lateral tongue protrusions (Berridge, 2000). Reaction scores were adjusted for any time offscreen in case activity differences caused mutant and wild-type mice to be out of view for different periods (Peciña et al., 1997).

As measures of general activity and exploration, we also scored rearing behaviors (scored as rising on the hind feet for at least $2 \mathrm{sec}$ ), locomotion (scored as three or more steps that moved the mouse more than one body length in $2 \mathrm{sec}$ ), and exploratory nose pokes in ventilation holes in the walls of the plastic cylindrical chambers (scored as penetration by the tip of the nose through a hole in the wall).

To prevent taste reactivity data from being biased by intermouse variations in intake, several steps were taken to standardize sampling of affective reactions across mice and to verify that the measure was sensitive to palatability "liking" in both mutant and wild-type mice. First, sampling was restricted to a standardized $5 \mathrm{sec}$ period that occurred immediately after each drink bout. Immediate postingestive affective reactions are especially sensitive to palatability (Grill et al., 1996) and are not distorted by the movements of voluntary drinking. The $5 \mathrm{sec}$ sampling period was identical for all mice and all drink bouts, so that potential differences in affective reactions between mutant and wild-type mice would not be obscured by any differences in intake. Furthermore, each serial bout of sucrose drinking (first bout, second bout, etc.) was analyzed separately so that the same serial position could be compared across mice to control for differences in affective reactions attributable to varying numbers of voluntary drink bouts. Finally, our use of three different sucrose concentrations, varying each by an order of magnitude $(0.01,0.1$, and $1.0 \mathrm{M}$ ), allowed assessment of whether taste reactivity measures were sensitive to palatability "liking" differences for mice by comparing affective reactions to markedly different sweetness levels. Because this study is the first to apply taste reactivity measures to mice, it seemed important to validate the measure by showing that sweeter tastes elicit more numerous positive hedonic reactions from mice, just as sweet tastes do from rats. This procedure also allowed assessment of whether mutant and wild-type mice differed in overall bias for positive versus negative affective reactions to sucrose tastes.

\section{Results}

\section{Food and water intake and body weight}

Food intake of DAT knockdown mutant mice was slightly higher than that of wild-type mice over a 4 week period (Fig. $1 A$ ). Mutant mice ate $21 \%$ more chow pellets/d on average than wild-type mice $\left(\right.$ ANOVA, $\left.F_{(1,295)}=72.19 ; p<0.001\right)$. Daily water intake was also $\sim 15 \%$ higher in DAT knockdown mutants $\left(F_{(1,295)}=\right.$ 40.27; $p<0.001)$. As might be expected from their higher food and water consumption, DAT knockdown mutant mice had slightly but consistently heavier body weights (Fig. $1 B$ ). All mice gained $\sim 5 \%$ body weight over a 1 month period $\left(F_{(3,81)}=2.70\right.$; $p=0.05)$ at similar rates of ascent $\left(F_{(3,81)}=0.05 ; p=\mathrm{NS}\right)$, and mutants were always $\sim 6 \%$ heavier than wild-type mice at every week throughout the month $\left(F_{(1,81)}=24.91 ; p<0.001\right)$.

\section{Runway performance}

DAT knockdown mutant mice showed enhanced acquisition and incentive performance for a sweet reward in the runway task (Fig. 2 ). The enhancement was especially evident during the incentive training phase when mice were learning the task $\left(F_{(1,97)}=25.75\right.$; $p<0.001)$. Initially, mice from both strains reached the goal slowly before learning, during goal box pre-exposure sessions $\left(F_{(1,59)}=5.25 ; p=0.65\right)$. DAT knockdowns reached the reward more quickly than wild types each day during the training phase (sessions $8-11, F_{(1,79)}=80.26 ; p<0.001$; each session Bonfer-
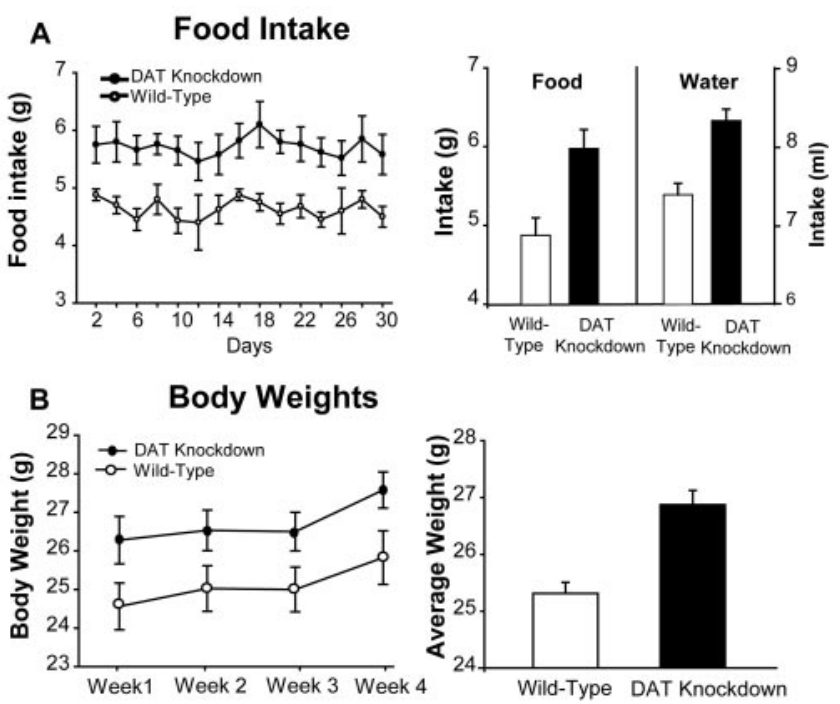

Figure 1. Food intake, water intake, and body weights. A, Daily food intake (grams) assessed over 4 weeks (left) and average daily food and water (milliliters) intake in DAT and knockdown mice (right). $B$, Body weights (grams) measured weekly (left) and averaged (right) in DAT knockdown and wild-type mice.

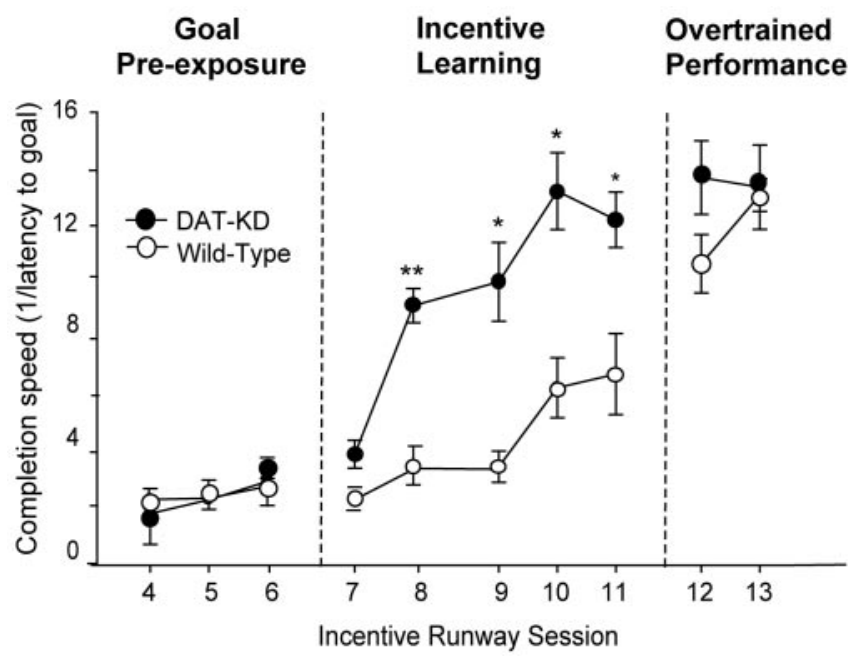

Figure 2. Incentive runway test. Incentive performance of DAT knockdown (KD) and wildtype mice measured as latency to reach the goal during the pre-exposure, learning, and overtraining phases of the runway task; ${ }^{*}$ Significant difference at $p<0.05 ;{ }^{* *} p<0.01$. B, Reversals and direct runs (bottom) bar graph shows that mutant mice tended to take direct, straight routes to the goal, whereas wild-type mice took circuitous routes that involved reversing direction and retracing steps before attaining goal.

roni, $p<0.05)$. Mutant DAT knockdowns reached their fastest asymptotic latencies to complete the task in session 10 , when wild-type mice were only halfway up their acquisition curve. Wild-type mice reached the same asymptotic latency to complete the task several days later in sessions 12 and 13. Once this completion latency was reached by both strains, there was no longer a difference between mutant and wild-type mice $\left(F_{(1,39)}=0.119\right.$; $p=\mathrm{NS}$ ), and the latency to reach the goal did not improve further. This indicated that by day 12 , the task had reached an overtraining phase or a possible motor ceiling.

It was crucial to distinguish whether faster task completion by mutant mice on days 8-11 reflected their higher incentive motivation to reach the goal or merely either enhanced curiosity to explore or enhanced motor capacity. If higher incentive motiva- 
tion causes hyperdopaminergic mutant mice to be more focused on obtaining a reward, they should spend less time in pauses and have fewer reversals than wild-type mice and instead should proceed more directly to the reward without distraction. Conversely, greater curiosity to explore without enhanced motivation for a reward could produce more investigatory reversals in the runway. If mutants are simply stronger and better runners, they should have faster motor running speeds even after subtraction of time spent in pauses and reversal. Thus, the pattern of runway behavior held potential information on why task completion differs between mutant and wild-type mice. Runway performance therefore was broken down into the following categories: (1) latency to leave the start box, (2) latency to reach the goal box in the runway, (3) pauses in the runway, (4) number of route reversals in the runway involving retracing of steps, (5) actual running speed (excluding time spent in pauses and reversals), and (6) latency to begin eating the Froot Loop after entering the goal box.

Breakdown analysis of runway performance during training revealed that mutant mice sprinted directly down the runway to the reward without pausing or reversing, compared with wildtype mice, which often paused and reversed $\left(F_{(1,159)}=44.5 ; p<\right.$ 0.001 ; Fig. 3). Mutants left the start box sooner than wild-type mice $\left(F_{(1,36)}=25.4 ; p<0.01\right)$. Mutants were only one-fourth as likely as wild-type mice to pause in the runway and were more likely instead to sprint without interruption to the goal, and the actual number of mutant pauses was only $1 / 10$ that of wild types (mean \pm SEM: mutant, $1.3 \pm 1.2$ pauses per trial; wild-type, $15.2 \pm 4.5$ pauses; $F_{(1,36)}=5.8 ; p<0.05$; Fig. $3 C$ ). Mutants also displayed only one-fifth as many investigatory reversals en route to the goal as wild type mice (mutant, $2.5 \pm 1.6$ reversals per trial; wild-type, $12.5 \pm 3.02$ reversals; $F_{(1,39)}=32.74 ; p<0.01$; Fig. $3 B$ ) and one-fifth the number of retracings of steps $\left(F_{(1,36)}=6.28\right.$; $p<0.05)$, and, instead, mutants chose more direct routes to the goal (Fig. 3B).

Similarly, in terms of durations, mutants spent only one-third the total time that wild-type mice did in pausing, reversing, and retracing while in the runway $\left(F_{(1,119)}=5.8 ; p<0.02\right.$; Fig. 4$)$. Once in the goal box, all mice began eating the Froot Loop within $5 \mathrm{sec}$ of entry. On initial analysis, there was no difference in the latency to eat the reward between mutant and wild-type mice. However, one mutant took more than twice as long to eat on one trial than any other mouse on any day and $>10$ times its own latencies on other trials. It therefore seemed reasonable to exclude that outlier trial, and when that was done, it became apparent that mutant mice had slightly shorter latencies overall to begin eating in the goal box than wild-type mice (mean \pm SEM: mutant, $1.8 \pm 1.1 \mathrm{sec}$; wild-type, $4.6 \pm 1.6 \mathrm{sec} ; F_{(1,41)}=13.08 ; p<$ $0.01)$. The duration of eating generally extended for the full $30 \mathrm{sec}$ allotted period until the mice were retrieved from the goal box.

By contrast to their difference in runway distractions, there was little difference in actual running speeds toward the goal between mutant and wild-type mice after subtracting out time spent in pausing and in reversals in the runway (Fig. $3 A$ ). Actual running speeds for all mice increased over phases of training from days 9 to $12\left(F_{(2,59)}=27.8 ; p<0.01\right)$, but mutant and wild-type mice had similar actual running speeds on both days $\left(F_{(1,59)}=\right.$ $0.29, p=$ NS). Thus mutants did not appear to be motorically faster than wild-type mice when actually running toward the goal. Instead, the entire difference in runway completion latency between mutants and wild-type mice appeared to be attributable to differences in time spent in distraction-related behaviors in the runway (start hesitance, pauses, reversals, and retracings). This
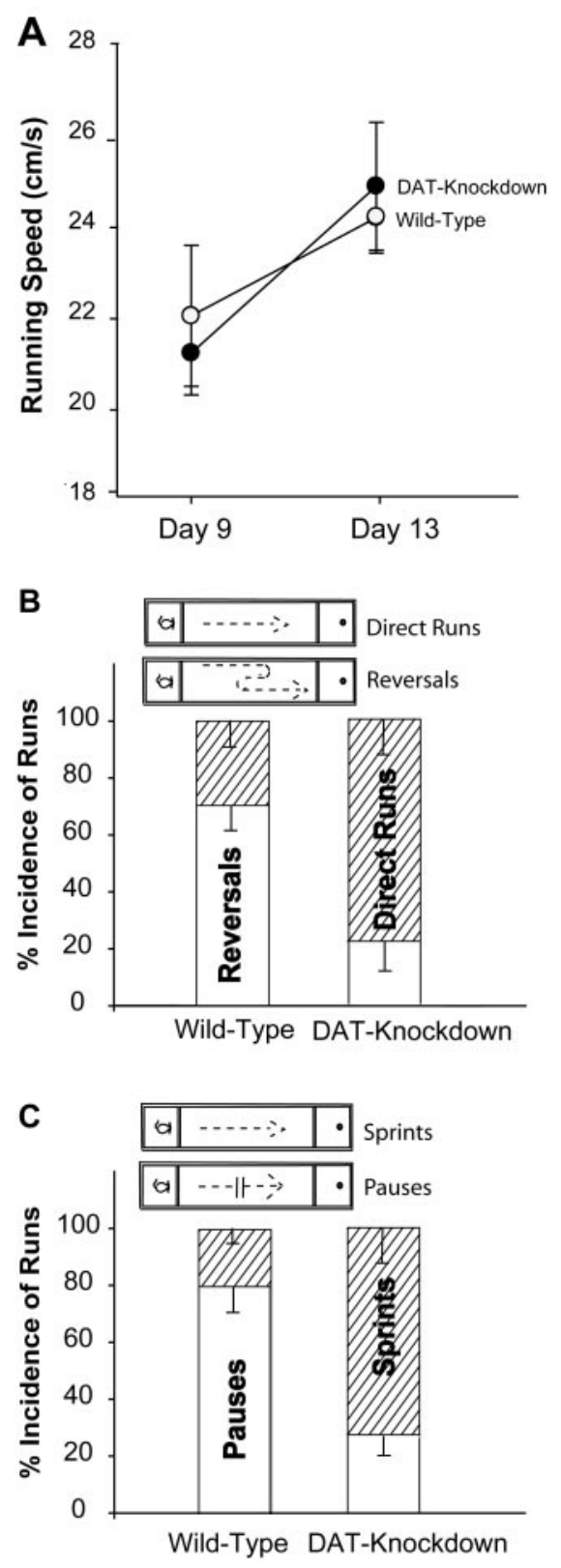

Figure 3. A, Actual motor running speeds of mutant and wild-type mice did not differ from each other (when behavioral distraction durations in the runway were factored out). All mice ran at similar speeds and improved equally from training days to test days. $B$, Mutant mice had a higher incidence of direct runs (runs without any directional reversals) than wild-type mice; $C$. Mutant mice had a higher incidence of sprints (uninterrupted runs without any pauses) than wild-type mice.

can be summarized by saying that mutant mice proceeded more directly to the reward than wild-type mice.

The mutant tendency to take more direct routes than wildtype mice was especially pronounced during the incentive learning phase in sessions 7-11 described above (a direct route was defined as a route without pause, reversal, or retracing of steps; $\left.F_{(1,39)}=10.818 ; p<0.01\right)$. The proportion of direct routes by wild-type mice did not rise until the overtraining phase $\left(F_{(1,39)}=\right.$ 32.749; $p<0.001$ ), when it finally approached that of the mutant mice (mean \pm SEM: mutant, $100 \pm 0 \%$ direct routes; wild-type, $91 \pm 18 \%)$. Finally, the identical latencies to complete the task of mutants and wild-type mice on initial trials and after overtraining further suggest that runway completion was not detectably 


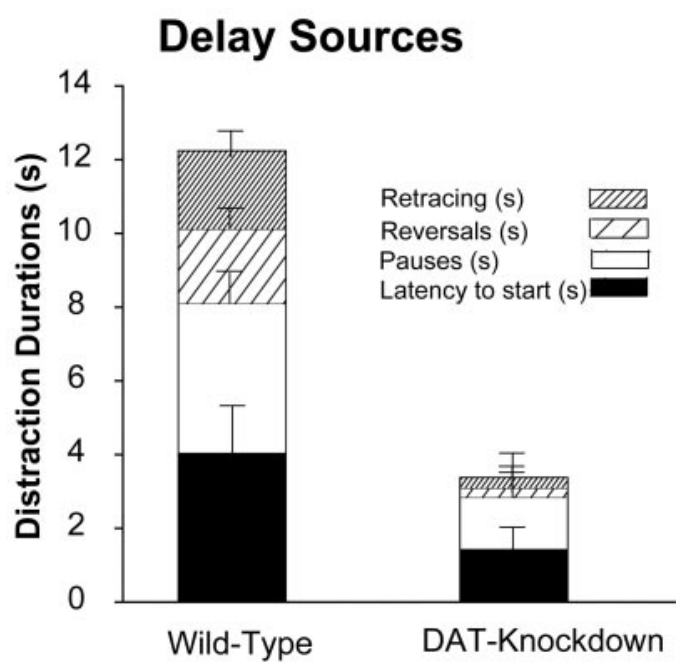

Figure 4. Source of runway completion latency differences. Shown is a breakdown of time spent in various runway behaviors (seconds of duration), which contributed to why wild-type mice were slower to reach the goal than mutant mice during training: latency to leave the start box, pauses in the runway, time spent in reversal of direction, and retracing of steps in runway.

affected by stable differences in motoric running ability between mutant and wild-type mice.

\section{Affective taste reactivity to sucrose}

DAT knockdown mice did not appear to "like" the taste of sucrose more than wild-type mice in the taste reactivity test (Fig. 5), despite their higher incentive motivation or "wanting" for a sweet reward and higher food intake. Three-way ANOVA [mouse strain (mutant vs wild-type) $\times$ bout order (first bout vs second bout vs third or later bouts) $\times$ sucrose concentration ( 0.01 vs 0.1 vs $1.0 \mathrm{M})$ ] revealed that hyperdopaminergic mutant mice displayed no more positive hedonic reactions to sucrose overall than wild-type mice $\left(F_{(1,215)}=1.40 ; p=N S\right)$. When drinking was broken into separate bouts, mutant and wild-type mice similarly displayed no significant difference in any bout (bout $X$ mouse strain interaction, $\left.F_{(2,215)}=0.60 ; p=\mathrm{NS}\right)$, although the first bout of drinking elicited more positive hedonic reactions from all mice than later bouts $\left(F_{(2,215)}=5.00 ; p<0.01\right)$.

Importantly, the sucrose concentration was a significant factor in determining "liking", in that sweeter solutions elicited more positive hedonic reactions from all mice than less sweet solutions $\left(F_{(2,215)}=3.22 ; p<0.05\right.$; Fig. 5$)$. Post hoc paired comparisons confirmed that more positive affective reactions were elicited by the sweetest $1.0 \mathrm{M}$ concentration than by the most diluted $0.01 \mathrm{M}$ solution (Bonferroni, $p<0.05$ ). Even when taken by themselves, hyperdopaminergic mutant mice were sensitive to sucrose concentration and displayed more positive hedonic reactions to the highest sucrose concentration than lower concentrations, primarily after third and later ingestive bouts (sucrose $\times$ bout interaction, $\left.F_{(4,172)}=3.78 ; p<0.01\right)$.

However, there was one difference between mutant and wildtype liking reactions at one sucrose concentration, indicated by a significant interaction between mutation and concentration $\left(F_{(2,174)}=3.921 ; p<0.05\right.$; Fig. 5). When mutant and wild-type mice were compared for each concentration separately, mutant mice still did not display more positive hedonic reactions than wild-type mice. At the low $(0.01 \mathrm{M})$ and medium $(0.1 \mathrm{M})$ sucrose concentrations, there was no difference in hedonic reactions between mutant and wild-type mice $\left(F_{(2,215)}=1.06 ; p=\right.$ NS). Strik- ingly, instead, however, at the highest sucrose concentration (1.0 M) that elicited the greatest number of hedonic reactions overall, DAT knockdown mutant mice actually displayed fewer positive hedonic reactions than wild-type mice $\left(F_{(1,54)}=4.73 ; p<0.05\right.$; Fig. 5). In other words, rather than "liking" sucrose more, mutants actually "liked" the most hedonic sweet stimulus slightly less than wild-type mice, and mutants "liked" the diluted sucrose concentrations about the same as wild-type mice.

Negative aversive reactions were infrequent, as would be expected for sucrose taste, typically averaging only $\sim 1 / 10$ the number of positive hedonic reactions (Fig. 5). The first drinking bout for some mice was occasionally followed by an aversive head shake, forelimb flail, or gape, but later bouts generally did not involve any aversive reactions. Mutant and wild-type mice did not differ in aversive reactions overall $\left(F_{(1,215)}=0.83 ; p=\mathrm{NS}\right)$ or at any sucrose concentration (mouse strain $X$ concentration interaction, $\left.F_{(2,215)}=0.66 ; p=\mathrm{NS}\right)$. Thus, it was clear that the taste of sucrose elicited primarily hedonic reactions and not aversive reactions from both mutant and wild-type mice. To summarize, sucrose never had a higher positive hedonic impact for DAT mutant mice than for wild-type mice and, if anything, had a lower hedonic impact for mutants at the most hedonic $1.0 \mathrm{M}$ concentration.

Finally, DAT knockdown mutants displayed more exploration-related behaviors than wild-type mice during the taste reactivity test. Elevated exploratory responses in mutants included nose pokes into wall ventilation holes, i.e., sampling air currents from outside the chamber $\left(F_{(1,47)}=10.88 ; p=0.002\right)$, locomotion across the test chamber $\left(F_{(1,14)}=6.2 ; p<0.01\right)$, and rearing behavior $\left(F_{(1,47)}=8.26 ; p<0.01\right)$. Higher mutant exploration in this environment contrasts to the reduced distraction in the runway task, where the mice had learned that a reward could be found, and is consistent with previous reports of enhanced novelty exploration (Zhuang et al., 2001).

\section{Discussion}

DAT knockdown mutant mice displayed a number of behavioral features consistent with the hypothesis that elevated synaptic dopamine enhanced the incentive value or "wanting" for a food reward (Berridge and Robinson, 1998). First, mutant mice consistently ate and drank more in their home cage than wild-type mice. Elevated daily food intake of mutant mice is the reverse of the aphagia and body weight deficit reported for dopaminedeficient mutant mice (Szczypka et al., 2001) and caused in rats by massive 6-OHDA lesions of dopamine projections to the nucleus accumbens and neostriatum (Zigmond and Stricker, 1972; Berridge and Robinson, 1998). Mutant hyperphagia might be explained if increased synaptic dopamine enduringly increased the incentive salience of food and water in the home cage for hyperdopaminergic mutant mice.

\section{Dopamine enhances wanting for sweet rewards}

The most compelling evidence for enhanced incentive salience came from the runway test. Mutant DAT knockdown mice appeared more focused than wild-type mice on obtaining a sweet reward in several ways. Mutant mice learned to complete the runway task for a sweet reward in fewer trials and consistently completed the task more quickly each day during training. The faster completion of the runway task by mutants was primarily attributable to their avoidance of delays within the runway that distracted wild-type mice. Mutant mice left the start box more quickly and proceeded more directly to the goal box during training. Mutants spent less time pausing in the runway, displayed 
fewer investigatory reversals, and less often retraced their steps en route to the sweet reward. Motor advantages appeared relatively unimportant to the latency to reach the goal, in that the actual motor running speed of mutant mice was no faster than that of wild-type mice either during or after training (aside from different durations spent in pauses and reversals). Nor did faster goal attainment by mutant mice seem explainable in terms of a greater mutant tendency to explore (Zhuang et al., 2001), although we confirmed their exploration tendency in the taste reactivity chamber. In the runway, where they had learned that the goal box held a reward, mutants actually made fewer investigatory reversals to examine stimuli en route and simply focused on reaching the goal box that held the sweet reward. Therefore, neither enhanced motor ability nor enhanced exploration explained why mutant mice were faster in reaching their runway goal.

The incentive salience hypothesis of dopamine function appears to be supported best by this pattern of runway behavior (Berridge and Robinson, 1998, 2003; Wyvell and Berridge, 2000; Dayan and Balleine, 2002; Robinson and Berridge, 2003; McClure et al., 2003; Zhang et al., 2003). The notion that DAT knockdown mutation elevates dopamine neurotransmission and so increases the perceived incentive value of reward stimuli, making the runway goal more "wanted" by mutant mice, could best explain why mutants were more eager to start the task, were less hesitant and distracted in the runway, and chose more direct routes to the goal during training.

\section{Enhanced reward learning?}

Faster acquisition of the runway task might also conceivably reflect enhancement of an associative learning mechanism that computes reward predictions, as suggested by associative learning models of dopamine function (Kelley, 1999; Berke and Hyman, 2000; Di Chiara, 2002; Everitt and Wolf, 2002; Ito et al., 2002; Montague and Berns, 2002; Schultz, 2002). Enhanced formation of associations would produce faster acquisition of the behavioral task. However, it is not entirely clear whether associative models of dopamine function would actually expect the increased tonic levels of synaptic dopamine, which are the chief aspect of dopamine function known so far to be elevated by DAT knockdown mutation (Zhuang et al., 2001), to enhance relevant phasic neuronal computations of prediction (Montague and Berns, 2002; Pagnoni et al., 2002; Schultz, 2002; Suri, 2002; Fiorillo et al., 2003; Shizgal and Arvanitogiannis, 2003). Thus, evaluation of the learning hypothesis may hang on whether phasic neuronal features specifically relevant to encoding associations are discovered in the future to be enhanced in DAT knockdown mutants. Finally, it is also worth noting that there are alternative explanations besides learning enhancement to explain mutants' runway behavior even for computational models of dopamine function in reward learning, at least for models that include an action or choice parameter separate from the prediction parameter (Dayan and Balleine, 2002; McClure et al., 2003).

\section{B. Aversive Reactions}

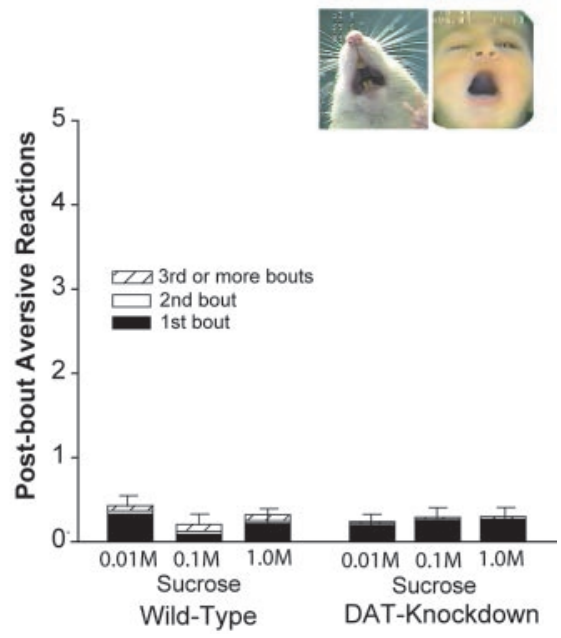

Figure 5. Affective liking reactions to sucrose tastes. $A$, Taste reactivity measure of positive orofacial affective reactions Frotrions, lateral tongue protrusions, and paw licking) displayed within $5 \mathrm{sec}$ after voluntary consumption of sucrose mutant mice were not different from wild-type mice at low and medium concentrations, and mutants actually displayed fewer

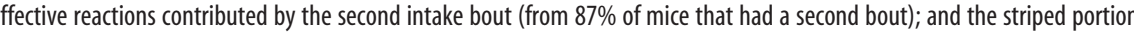
mice to produce an illustrative photograph, so an example from a rat is substituted here) (human photographs from Steiner et al. (2001), rat photograph from Berridge (2000)].

One alternative explanation for faster runway acquisition is that more rapid learning was a secondary consequence of higher incentive salience attributed to runway stimuli. Hyperdopamine mutant mice may have paid more attention to "wanted" rewardrelated stimuli during training. Making stimuli more attentiongrabbing is likely to facilitate learning about them, in addition to motivating approach and consumption behavior (Gray et al., 1999; Pearce and Bouton, 2001; Dickinson and Balleine, 2002; McClure et al., 2003). A limbic-cortical neural mechanism has been suggested by Sarter and Bruno (2000) and NeighMcCandless et al. (2002) to mediate attentional processing facilitated by incentive salience, via projections from the nucleus accumbens to the basal nucleus, which in turn modulates acetylcholine projections to the neocortex that influence attention. Attention to reward-related stimuli also might conceivably be enhanced in knockdown mutant mice by alteration in dopamine projections to the central amygdala or prefrontal cortex (Servan-Schreiber et al., 1998; Holland et al., 2000; Baxter and Murray, 2002; Cardinal et al., 2002; Horvitz, 2002).

\section{Dopamine fails to enhance sweet "liking"}

Hyperdopaminergic knockdown mutant mice failed to display enhanced "liking" reactions to sucrose taste in the taste reactivity test, despite their apparently enhanced incentive motivation for a sweet reward in the runway test. Thus dopamine may enhance "wanting" for sweet rewards without increasing sweetness "liking". "Liking" reactions in the taste reactivity test appeared to remain sensitive to differences in the hedonic impact of sweetness for these mice. For example, more positive hedonic reactions were elicited overall by the concentrated $1.0 \mathrm{M}$ taste (which contained 100 -fold more sucrose) than by the most diluted solution, but mutant and wild-type mice did not differ in their number of 
"liking" reactions at low and moderate sucrose concentrations, and the highest sucrose concentration actually elicited fewer positive hedonic reactions from mutants than from wild-type mice.

The incentive salience hypothesis does not actually require that "liking" reactions be reduced in hyperdopaminergic mutants, only that they not be elevated. However, a decreased "liking" reaction helps dramatically illustrate the independence between "wanting" and "liking" predicted by the hypothesis. In that sense, decreased "liking" is compatible and even useful as evidence in favor of incentive salience interpretations when accompanying elevated dopamine function that causes increased "wanting". Our results are reminiscent of similar reports of increased wanting accompanied by slightly decreased "liking" produced by amphetamine microinjection in the nucleus accumbens and by electrical stimulation of the medial forebrain bundle (Berridge and Valenstein, 1991; Wyvell and Berridge, 2000). The explanation for why increased "wanting" caused by mesolimbic activation is sometimes accompanied by decreased "liking" may have to do with the existence of separable mechanisms of liking within the nucleus accumbens shell that use opioid, GABA, and related neurochemical signals on spiny neurons to cause "liking" or "disliking" reactions to sweet tastes (Peciña and Berridge, 2000; Reynolds and Berridge, 2002). Finally, our finding that elevated synaptic dopamine caused by DAT knockdown mutation caused increased "wanting" for a sweet reward but not increased "liking" for sweet tastes also seems consistent with studies of human subjects that report extracellular dopamine in the accumbens or striatum to be better correlated to subjective ratings of wanting for a drug or food reward than to subjective ratings of pleasure (Leyton et al., 2002; Volkow et al., 2002) and with studies that report that human subjective ratings of pleasure for amphetamine or cigarettes are less suppressed by dopamine antagonists than ratings of craving for those same rewards (Brauer and De Wit, 1997; Brauer et al., 1997, 2001; Wachtel et al., 2002).

\section{Conclusion}

Our study is the first attempt to dissect altered rewards in hyperdopaminergic mutant mice into behavioral and psychological components such as incentive motivation "wanting", affective hedonic "liking", and associative learning. These results suggest that DAT knockdown mutant mice have higher "wanting" for a learned sweet reward but not greater "liking" for sweet rewards compared with wild-type mice. The question of altered associative learning remains open. As a caveat, we note that DAT knockdown, as any other single mutation, must produce multiple consequences and adaptations beyond the primary intended consequence, in this case, elevation of synaptic dopamine. It would be helpful to confirm these conclusions with other mutations that elevate synaptic dopamine to be confident that hyperdopaminergic function is the cause of the behavioral features reported here. For now, however, these results point to a special role for dopamine in mediating the incentive salience of rewards, which interacts with learned performance of a goal-directed task.

Beyond providing insight into brain dopamine function in motivation for sweet rewards, these data on incentive motivation and hedonic impact dovetail with recent suggestions that related changes in mesolimbic systems, such as those caused in drug addicts by neural sensitization, may be important in motivational features of drug addiction (Robinson and Berridge, 2000; Vanderschuren and Kalivas, 2000; Hyman and Malenka, 2001; De Vries and Shippenberg, 2002; Everitt and Wolf, 2002; Robinson and Berridge, 2003). Higher incentive motivation for sweet rewards in hyperdopaminergic mutant mice seems consistent with the possibility that related sensitization of mesolimbic neurotransmission might produce excessive "wanting" of drug rewards in human addicts.

\section{References}

Baxter MG, Murray EA (2002) The amygdala and reward. Nat Rev Neurosci 3:563-573.

Berke JD, Hyman SE (2000) Addiction, dopamine, and the molecular mechanisms of memory. Neuron 25:515-532.

Berridge KC (2000) Measuring hedonic impact in animals and infants: microstructure of affective taste reactivity patterns. Neurosci Biobehav Rev 24:173-198.

Berridge KC, Robinson TE (1998) What is the role of dopamine in reward: hedonic impact, reward learning, or incentive salience? Brain Res Rev 28:309-369.

Berridge KC, Robinson TE (2003) Parsing reward. Trends Neurosci 26:507513.

Berridge KC, Valenstein ES (1991) What psychological process mediates feeding evoked by electrical stimulation of the lateral hypothalamus? Behav Neurosci 105:3-14.

Bosse R, Fumagalli F, Jaber M, Giros B, Gainetdinov RR, Wetsel WC, Missale C, Caron MG (1997) Anterior pituitary hypoplasia and dwarfism in mice lacking the dopamine transporter. Neuron 19:127-138.

Brauer LH, De Wit H (1997) High dose pimozide does not block amphetamine-induced euphoria in normal volunteers. Pharmacol Biochem Behav 56:265-272.

Brauer LH, Goudie AJ, de Wit H (1997) Dopamine ligands and the stimulus effects of amphetamine: animal models versus human laboratory data. Psychopharmacology 130:2-13.

Brauer LH, Cramblett MJ, Paxton DA, Rose JE (2001) Haloperidol reduces smoking of both nicotine-containing and denicotinized cigarettes. Psychopharmacology 159:31-37.

Budygin EA, John CE, Mateo Y, Jones SR (2002) Lack of cocaine effect on dopamine clearance in the core and shell of the nucleus accumbens of dopamine transporter knock-out mice. J Neurosci 22:RC222(1-4).

Cardinal RN, Parkinson JA, Hall J, Everitt BJ (2002) Emotion and motivation: the role of the amygdala, ventral striatum, and prefrontal cortex. Neurosci Biobehav Rev 26:321-352.

Dayan P, Balleine BW (2002) Reward, motivation, and reinforcement learning. Neuron 36:285-298.

De Vries TJ, Shippenberg TS (2002) Neural systems underlying opiate addiction. J Neurosci 22:3321-3325.

Di Chiara G (2002) Nucleus accumbens shell and core dopamine: differential role in behavior and addiction. Behav Brain Res 137:75-114.

Dickinson A, Balleine B (2002) The role of learning in the operation of motivational systems. In: Stevens' handbook of experimental psychology: learning, motivation, and emotion, Ed 3 (Gallistel CR, ed), pp 497-534. New York: Wiley.

Everitt BJ, Wolf ME (2002) Psychomotor stimulant addiction: a neural systems perspective. J Neurosci 22:3312-3320.

Everitt BJ, Dickinson A, Robbins TW (2001) The neuropsychological basis of addictive behaviour. Brain Res Rev 36:129-138.

Feurté S, Nicolaidis S, Berridge KC (2000) Conditioned taste aversion in rats for a threonine-deficient diet: demonstration by the taste reactivity test. Physiol Behav 68:423-429.

Fiorillo CD, Tobler PN, Schultz W (2003) Discrete coding of reward probability and uncertainty by dopamine neurons. Science 299:1898-1902.

Giros B, Jaber M, Jones SR, Wightman RM, Caron MG (1996) Hyperlocomotion and indifference to cocaine and amphetamine in mice lacking the dopamine transporter. Nature 379:606-612.

Gray JA, Kumari V, Lawrence N, Young AMJ (1999) Functions of the dopaminergic innervation of the nucleus accumbens. Psychobiology 27:225-235.

Gray RW, Cooper SJ (1995) Benzodiazepines and palatability: taste reactivity in normal ingestion. Physiol Behav 58:853-859.

Gray RW, Cooper SJ (1996) D-Fenfluramine's effects on normal ingestion assessed with taste reactivity measures. Physiol Behav 59:1129-1135.

Grill HJ, Roitman MF, Kaplan JM (1996) A new taste reactivity analysis of the integration of taste and physiological state information. Am J Physiol 271:R677-R687.

Holland PC, Han JS, Gallagher M (2000) Lesions of the amygdala central 
nucleus alter performance on a selective attention task. J Neurosci 20:6701-6706.

Horvitz JC (2002) Dopamine gating of glutamatergic sensorimotor and incentive motivational input signals to the striatum. Behav Brain Res 137:65-74.

Hyman SE, Malenka RC (2001) Addiction and the brain: the neurobiology of compulsion and its persistence. Nat Rev Neurosci 2:695-703.

Ito R, Dalley JW, Robbins TW, Everitt BJ (2002) Dopamine release in the dorsal striatum during cocaine-seeking behavior under the control of a drug-associated cue. J Neurosci 22:6247-6253.

Kelley AE (1999) Functional specificity of ventral striatal compartments in appetitive behaviors. Ann NY Acad Sci 877:71-90.

Kelley AE, Berridge KC (2002) The neuroscience of natural rewards: relevance to addictive drugs. J Neurosci 22:3306-3311.

Koob GF, Le Moal M (2001) Drug addiction, dysregulation of reward, and allostasis. Neuropsychopharmacology 24:97-129.

Laakso A, Mohn AR, Gainetdinov RR, Caron MG (2002) Experimental genetic approaches to addiction. Neuron 36:213-228.

Leyton M, Boileau I, Benkelfat C, Diksic M, Baker G, Dagher A (2002) Amphetamine-induced increases in extracellular dopamine, drug wanting, and novelty seeking: a PET/[11C]raclopride study in healthy men. Neuropsychopharmacology 27:1027-1035.

McClure SM, Daw ND, Montague PR (2003) A computational substrate for incentive salience. Trends Neurosci 26:423-428.

Montague PR, Berns GS (2002) Neural economics and the biological substrates of valuation. Neuron 36:265-284.

Neigh-McCandless G, Kravitz BA, Sarter M, Bruno JP (2002) Stimulation of cortical acetylcholine release following blockade of ionotropic glutamate receptors in nucleus accumbens. Eur J Neurosci 16:1259-1266.

Pagnoni G, Zink CF, Montague PR, Berns GS (2002) Activity in human ventral striatum locked to errors of reward prediction. Nat Neurosci 5:97-98.

Pearce JM, Bouton ME (2001) Theories of associative learning in animals. Annu Rev Psychol 52:111-139.

Peciña S, Berridge KC (2000) Opioid eating site in accumbens shell mediates food intake and hedonic "liking": map based on microinjection Fos plumes. Brain Res 863:71-86.

Peciña S, Berridge KC, Parker LA (1997) Pimozide does not shift palatability: separation of anhedonia from sensorimotor suppression by taste reactivity. Pharmacol Biochem Behav 58:801-811.

Pelchat ML, Grill HJ, Rozin P, Jacobs J (1983) Quality of acquired responses to tastes by Rattus norvegicus depends on type of associated discomfort. J Comp Psychol 97:140-153.

Reynolds SM, Berridge KC (2002) Positive and negative motivation in nucleus accumbens shell: bivalent rostrocaudal gradients for GABA-elicited eating, taste "liking"/“disliking" reactions, place preference/avoidance, and fear. J Neurosci 22:7308-7320.

Robinson TE, Berridge KC (2000) The psychology and neurobiology of addiction: an incentive-sensitization view. Addiction 95:91-117.

Robinson TE, Berridge KC (2003) Addiction. Annu Rev Psychol 54:25-53.

Salamone JD, Correa M (2002) Motivational views of reinforcement: implications for understanding the behavioral functions of nucleus accumbens dopamine. Behav Brain Res 137:3-25.

Sarter M, Bruno JP (2000) Cortical cholinergic inputs mediating arousal, attentional processing and dreaming: differential afferent regulation of the basal forebrain by telencephalic and brainstem afferents. Neuroscience 95:933-952.
Schultz W (2002) Getting formal with dopamine and reward. Neuron 36:241-263.

Servan-Schreiber D, Bruno RM, Carter CS, Cohen JD (1998) Dopamine and the mechanisms of cognition: part I. A neural network model predicting dopamine effects on selective attention. Biol Psychiatry 43:713-722.

Shizgal P, Arvanitogiannis A (2003) Neuroscience: gambling on dopamine. Science 299:1856-1858.

Sora I, Wichems C, Takahashi N, Li XF, Zeng Z, Revay R, Lesch KP, Murphy DL, Uhl GR (1998) Cocaine reward models: conditioned place preference can be established in dopamine- and in serotonin-transporter knockout mice. Proc Natl Acad Sci USA 95:7699-7704.

Spielewoy C, Gonon F, Roubert C, Fauchey V, Jaber M, Caron MG, Roques BP, Hamon M, Betancur C, Maldonado R, Giros B (2000) Increased rewarding properties of morphine in dopamine-transporter knockout mice. Eur J Neurosci 12:1827-1837.

Steiner JE, Glaser D, Hawilo ME, Berridge KC (2001) Comparative expression of hedonic impact: affective reactions to taste by human infants and other primates. Neurosci Biobehav Rev 25:53-74.

Suri RE (2002) TD models of reward predictive responses in dopamine neurons. Neural Netw 15:523-533.

Szczypka MS, Kwok K, Brot MD, Marck BT, Matsumoto AM, Donahue BA, Palmiter RD (2001) Dopamine production in the caudate putamen restores feeding in dopamine-deficient mice. Neuron 30:819-828.

Vanderschuren L, Kalivas PW (2000) Alterations in dopaminergic and glutamatergic transmission in the induction and expression of behavioral sensitization: a critical review of preclinical studies. Psychopharmacology 151:99-120.

Volkow ND, Wang GJ, Fowler JS, Logan J, Gatley SJ, Wong C, Hitzemann R, Pappas NR (1999) Reinforcing effects of psychostimulants in humans are associated with increases in brain dopamine and occupancy of D-2 receptors. J Pharmacol Exp Ther 291:409-415.

Volkow ND, Wang GJ, Fowler JS, Logan J, Jayne M, Franceschi D, Wong C, Gatley SJ, Gifford AN, Ding YS, Pappas N (2002) "Nonhedonic" food motivation in humans involves dopamine in the dorsal striatum and methylphenidate amplifies this effect. Synapse 44:175-180.

Wachtel SR, Ortengren A, de Wit H (2002) The effects of acute haloperidol or risperidone on subjective responses to methamphetamine in healthy volunteers. Drug Alcohol Depend 68:23-33.

White FJ (2002) A behavioral/systems approach to the neuroscience of drug addiction. J Neurosci 22:3303-3305.

Wise RA (1985) The anhedonia hypothesis: mark III. Behav Brain Sci 8:178-186.

Wyvell CL, Berridge KC (2000) Intra-accumbens amphetamine increases the conditioned incentive salience of sucrose reward: enhancement of reward "wanting" without enhanced "liking" or response reinforcement. J Neurosci 20:8122-8130.

Zhang M, Balmadrid C, Kelley AE (2003) Nucleus accumbens opioid, GABAergic, and dopaminergic modulation of palatable food motivation: contrasting effects revealed by a progressive ratio study in the rat. Behav Neurosci 117:202-211.

Zhuang X, Oosting RS, Jones SR, Gainetdinov PR, Miller GW, Caron MG, Hen R (2001) Hyperactivity and impaired response habituation in hyperdopaminergic mice. Proc Natl Acad Sci USA 98:1982-1987.

Zigmond MJ, Stricker EM (1972) Deficits in feeding behavior after intraventricular injection of 6-hydroxydopamine in rats. Science 177:12111214. 